\title{
Flood risk in the UK: current and future
}

\author{
N. S. Reynard, A. L. Kay \& S. M. Crooks \\ Centre for Ecology and Hydrology, Wallingford, UK
}

\begin{abstract}
There is a widely-held view that future climate change will increase flood risk in the UK. Extensive modelling studies have been undertaken at CEH to test this hypothesis. The development of continuous river flow simulation techniques for flood frequency estimation now provides a new methodology to predict climate change impacts on flood flows. This technique has been applied to a range of British catchments (work funded by the UK Department for the Environment, Food and Rural Affairs) to assess potential changes in flood risk and directly inform policy development for flood defence scheme appraisal.

Using observed climate variables and river flows, the catchment models have been calibrated and validated for the present day. A wide range of climate change scenarios have then been applied to the driving climate data and river flow time series simulated indicative of future time horizons. The flood characteristics of the future have been compared with those of the current. There are many uncertainties associated with this type of climate change impact analysis, including the choice of which Global Climate Model (GCM) to use to derive scenarios of change and precisely how coarse-resolution climate changes (from GCMs) are "downscaled" to the catchment level, as well as hydrological modelling uncertainty. These uncertainties have been assessed, and their effects on the results are discussed.

Despite the belief that flood flows will increase in the future, there is no clear message about the size, or even the direction of change in flood flow magnitudes in the UK. Changes in flood flows are catchment-specific, being driven by hydrological variability, such as geology, and the seasonal distribution of rainfall.

Keywords: flood risk, river flow modelling, climate change, uncertainty.
\end{abstract}




\section{Introduction}

It is now widely accepted that human activity is having an affect on the global climate. A warmer world will, in general, lead to an intensified hydrological cycle. How this translates to the catchment scale, and to changes in catchment flood risk in the UK, remains unclear, despite frequent assertions that climate change will lead to increased flooding across the country. This paper describes work undertaken at the Centre for Ecology and Hydrology (CEH), for the UK Department for the Environment, Food and Rural Affairs (Defra) and the Environment Agency for England and Wales (EA), to test this hypothesis. Moreover the work described here is being used directly by Defra to inform their development of policy for incorporating climate change within flood defence scheme appraisal guidance.

Techniques of continuous flow simulation have been used to estimate flood frequency in the UK [1]. These models are driven by time series of climate variables and therefore permit the application of non-stationary climate series, previously difficult using statistical methods of flood frequency estimation. The potential changes to flood flows in a number of British catchments, under a range of climate change scenarios, have been studied.

\section{Study catchments}

The 10 catchments were selected to have a good geographical spread (Figure 1), and to incorporate a range of catchment areas, permeabilities and land uses. Table 1 summarises some of the catchment characteristics. The Anton provides an example of a highly permeable chalk catchment, whereas the upland Duddon in the Cumbrian Mountains has a low permeability. The Rea is a highly urbanised catchment, contrasted with the rural Lymn. The Halladale in northern Scotland was included for comparison with catchments having a more southern climate. Two middle-sized catchments were selected; the Ouse in northern England and the Severn (Bewdley) in the west, and the two large catchments $\left(\sim 10,000 \mathrm{~km}^{2}\right)$ of the Thames and Severn at haw Bridge.

\section{Hydrological models}

Due to the different nature and size of the study catchments two types of hydrological model have been used. Full descriptions of the models, the calibration and validation procedures for these study catchments, and a discussion of model uncertainty may be found in the final project report [2].

The CLASSIC (Climate and Land-use Scenario Simulation In Catchments) model [3] was developed for estimating the impacts of climate and land use change in large catchments. It has been further developed and was used in earlier climate change impact studies [4-6]. This semi-distributed model comprises three component modules (models for the soil water balance, the hydrological response and the channel routing). It is applied on a grid square framework with climatic inputs of rainfall and potential evapotranspiration (PE) to each grid 
square. For the smaller catchments the Probability Distributed Moisture (PDM) model is used [7, 8]. This is a conceptually-based catchment model that attempts to represent non-linearity in the transformation from rainfall to runoff by using a probability distribution of soil moisture storage. This determines the timevarying proportion of the catchment that contributes to runoff, through either 'fast' or 'slow' pathways

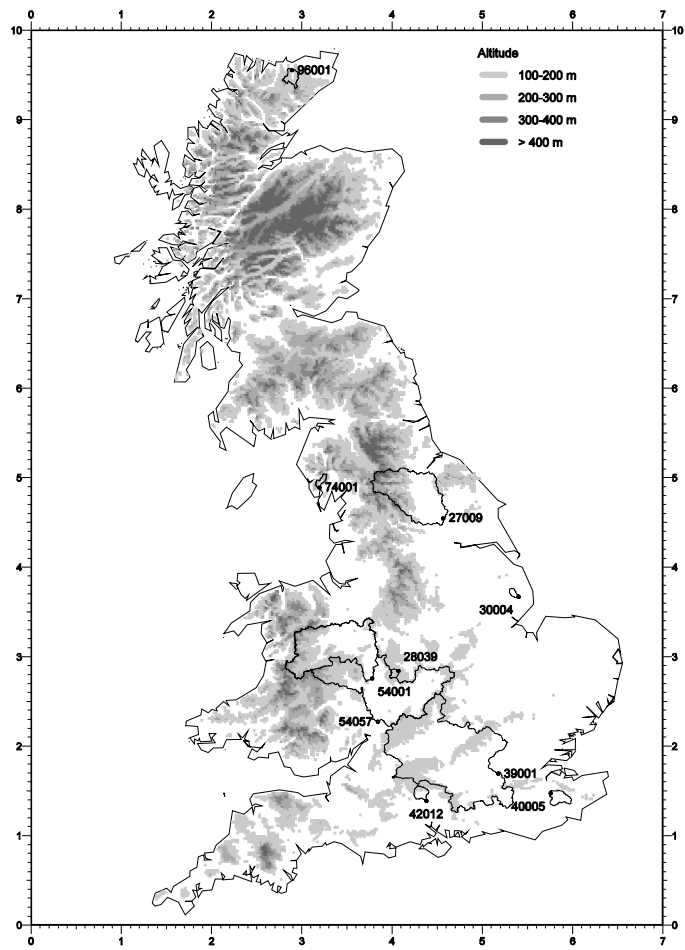

Figure 1: Topography and location of the 10 study catchments.

\section{Climate change scenarios}

\subsection{UK Climate Impacts Programme (UKCIP) 2002 scenarios (UKCIP02)}

The UKCIP02 scenarios [9] comprise a set of four alternative future climates spanning a range of global emissions, namely the low, medium-low, mediumhigh and high emissions scenarios, for three future 30-year time slices centred on the 2020s, 2050s and 2080s. The scenarios are presented as monthly changes, compared with the 1961-1990 baseline, for 15 climate variables, for a $50 \mathrm{x} 50 \mathrm{~km}$ grid across the UK. For hydrological modelling purposes, changes in rainfall and $\mathrm{PE}$ are required, the latter being calculated using the climate variables of temperature, wind speed, relative humidity and net radiation. 
Table 1: Catchment characteristics for the 10 study catchments.

\begin{tabular}{|l|l|c|c|c|c|}
\hline Number & Catchment name & $\begin{array}{c}\text { Area } \\
\left(\mathrm{km}^{2}\right)\end{array}$ & $\begin{array}{c}\text { Base } \\
\text { flow } \\
\text { index }\end{array}$ & $\begin{array}{c}\text { Mean } \\
\text { flow } \\
\left(\mathrm{m}^{3} \mathrm{~s}^{-1}\right)\end{array}$ & $\begin{array}{l}\text { Average } \\
\text { annual } \\
\text { rainfall } \\
1961-1990 \\
(\mathrm{~mm})\end{array}$ \\
\hline 27009 & Ouse at Skelton & 3315 & 0.43 & 49.0 & 900 \\
\hline 28039 & $\begin{array}{l}\text { Rea at Calthorpe } \\
\text { Park }\end{array}$ & 74 & 0.48 & 0.8 & 781 \\
\hline 30004 & $\begin{array}{l}\text { Lymn at Partney } \\
\text { Mill }\end{array}$ & 62 & 0.66 & 0.5 & 685 \\
\hline 39001 & $\begin{array}{l}\text { Thames at } \\
\text { Kingston }\end{array}$ & 9948 & 0.64 & 66.6 & 706 \\
\hline 40005 & $\begin{array}{l}\text { Beult at Stile } \\
\text { Bridge }\end{array}$ & 277 & 0.24 & 2.1 & 690 \\
\hline 42012 & $\begin{array}{l}\text { Anton at } \\
\text { Fullerton }\end{array}$ & 185 & 0.96 & 1.9 & 773 \\
\hline 54001 & $\begin{array}{l}\text { Severn at } \\
\text { Bewdley }\end{array}$ & 4325 & 0.53 & 61.9 & 913 \\
\hline 54057 & $\begin{array}{l}\text { Severn at Haw } \\
\text { Bridge }\end{array}$ & 9895 & 0.57 & 105.3 & 792 \\
\hline 74001 & $\begin{array}{l}\text { Duddon at } \\
\text { Duddon Hall }\end{array}$ & 86 & 0.28 & 5.00 & 2265 \\
\hline 96001 & $\begin{array}{l}\text { Halladale at } \\
\text { Halladale }\end{array}$ & 205 & 0.25 & 5.00 & 1102 \\
\hline
\end{tabular}

The UKCIP02 scenarios have been applied to the daily rainfall baseline time series in such a way as to also reproduce the changes in seasonal daily rainfall frequency described in the UKCIP02 Technical Report [2]. The monthly percentage changes in $\mathrm{PE}$ have been applied in a simple proportional way to the daily time step of PE used to drive the models.

\subsection{Statistical downscaling}

The Statistical Downscaling Model (SDSM) [10] has been used to provide daily time series of rainfall to drive the hydrological model CLASSIC. Rainfall time series were developed for each of the model grid boxes for each catchment. One set of results was produced using the multi-site, spatially correlated, version of SDSM [11] and one with a single site model that does not account for the spatial dependence between grids. This downscaling method was used to derive continuous time series of daily rainfall data for the $20 \mathrm{~km}$ grid squares for the Severn at Bewdley and the $10 \mathrm{~km}$ grid squares for the Ouse from 1961 to 2099 for the A2 and B2 emissions scenarios [2,12]. 


\subsection{Dynamic downscaling - use of Regional Climate Model output}

For dynamic downscaling the hourly output from the $25 \mathrm{~km}$ RCM has been used directly to drive both the PDM and CLASSIC models. Whereas the UKCIP02 scenarios are implemented by perturbing a baseline (1961-1990) climatology, both the statistically and dynamically downscaled scenarios also produce alternative baselines.

Figure 2 is the flood frequency curves (relating average return period, in years, to peak flow) for the Severn at Bewdley, showing the observed flows (dotted line), the flows modelled from the observed rainfall (solid line), the SDSM A2 baseline (long-dashed line), the SDSM B2 baseline (short-dashed line) and the RCM baseline (dot-dashed line). For this catchment there is good agreement between the observed and modelled curves, and, indeed, the flood frequency curves generated using the SDSM for both the A2 and B2 control periods. The curve from the RCM rainfall appears considerably more extreme, and this is the case for five of the ten study catchments. For other catchments however, notably the Thames, the correspondence is better.

\section{Flood frequency analysis under climate change}

The partial duration, or peaks-over-threshold (POT), method [13] was used to fit frequency distributions to the modelled baseline and scenario 30-year flow series. An average rate of three independent events per year was used for the frequency analyses. The magnitudes of the POT were fitted using the generalised Pareto distribution, with the peak arrival times assumed to correspond to a Poisson distribution. Fitting was carried out using the method of probability weighted moments [14].

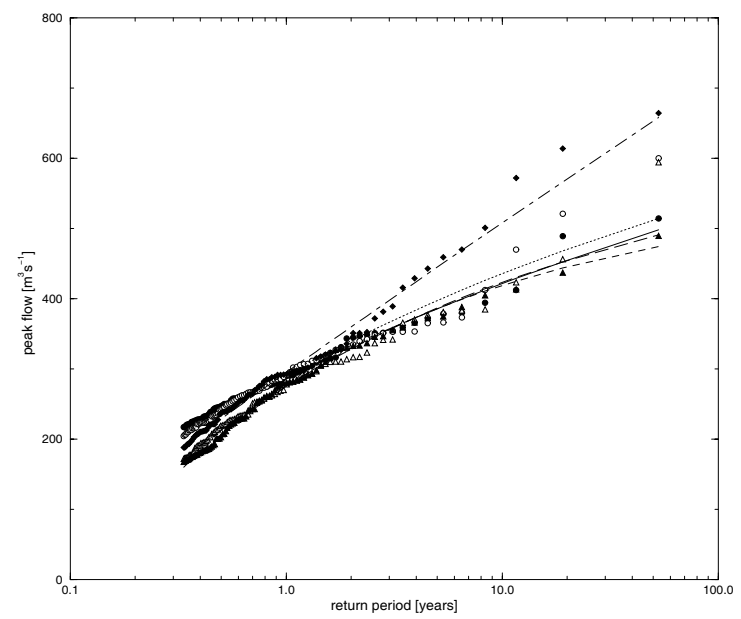

Figure 2: Comparison of baseline flood frequency curves for the Severn at Bewdley. 


\subsection{UKCIP02 scenarios}

The percentage change in flood flows for the ten catchments under the UKCIP02 Medium-High scenario are listed in Table 2 for the 5 and 50-year return periods for the 2050s and the 2080s. Across all catchments the impacts vary in both size and direction of change. Only for the Duddon is there an increase in flows under all scenarios for all return periods. The over-riding factor appears to be the location (in terms of the future, rather than the current climate). These factors out-weigh the potential patterns in the impacts due to either catchment size or geology. For example, the Halladale in Scotland (small and hydrologicallyresponsive) does not show the same impact as the Duddon despite their similar catchment characteristics. The UKCIP02 scenarios show less change in winter precipitation for the Halladale than for the Duddon in the north west of England.

Table 2: Percentage changes in flows for the UKCIP02 Medium-High scenario.

\begin{tabular}{lcccc}
\hline \multirow{2}{*}{ Catchment } & \multicolumn{2}{c}{$2050 \mathrm{~s}$} & \multicolumn{2}{c}{$2080 \mathrm{~s}$} \\
\cline { 2 - 5 } & 5 -year & 50 -year & 5-year & 50-year \\
\hline Ouse at Skelton & -0.3 & -3.9 & 0.4 & -7.1 \\
Rea at Calthorpe Park & 7.3 & -1.3 & 2.8 & -7.6 \\
Lymn at Partney Mill & -4.0 & -8.3 & -4.5 & -13.9 \\
Thames at Kingston & -2.9 & -1.2 & -2.5 & 0.6 \\
Beult at Stile Bridge & 5.1 & -4.6 & 9.8 & -11.2 \\
Anton at Fullerton & -1.8 & 4.7 & -1.7 & 8.5 \\
Severn at Bewdley & -3.0 & -0.9 & -4.7 & -6.7 \\
Severn at Haw Bridge & -1.6 & 1.0 & -0.5 & 4.2 \\
Duddon at Duddon Hall & 6.9 & 4.2 & 10.1 & 21.9 \\
Halladale at Halladale & -2.1 & 2.0 & -2.8 & -2.9 \\
\hline
\end{tabular}

For most catchments the percentage changes follow a similar pattern across the four emission scenarios and time slices. The main exception is the urban Rea where the Medium-Low and Low scenarios for the 2050s and Low scenario for the 2080s show an increase at the 50-year return period, whereas the other scenarios show a decrease. In general the impact of the higher winter rainfall is offset by the increase in PE and the, on average, hotter, drier conditions during the summer and autumn.

\subsection{Statistical downscaling}

Figure 3 shows the flood frequency curves derived for the A2 and B2 emission scenarios [12] for three time slices, the baseline period of 1961-1990 using observed rainfall (solid line, filled squares) and using SDSM modelled rainfall (dotted line, open circles), the 2050s (short dashed, open triangle) and the 2080s (long dashed, open diamond). In addition a flood frequency curve was also derived for the single-site (independent grid square) rainfall time series for the 
baseline period (dotted line, open squares). The difference between the two dotted lines in Figure 3, and comparing these curves to the solid "observed" baseline, gives an indication of the positive contribution of using spatially correlated rainfall fields from SDSM in generating flood runoff. The single-site, uncorrelated, rainfall for the model grids greatly under-estimates the baseline flood frequencies as the large-scale rainfall events, which are more likely to produce floods in catchments as large as the Ouse, are not being simulated.

27009
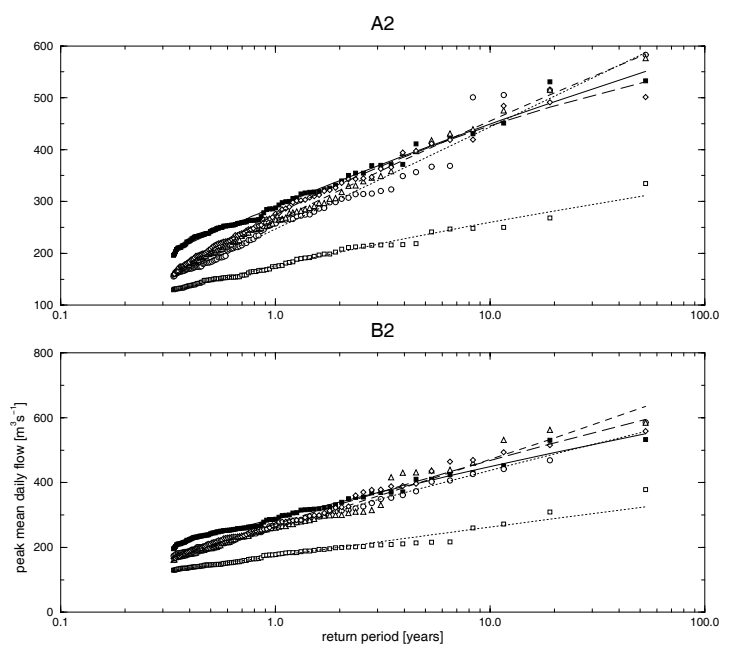

Figure 3: Flood frequency curves for the Ouse under the A2 and B2 scenarios.

The B2 scenario shows an increase in flood frequency for all return periods greater than five years and for the Ouse the two emissions scenarios have an opposite impact. The highest increase is for the B2 scenario for the 2050s for return periods greater than 20 years. It should be noted that the B2 scenario used for the statistical downscaling is from a "real" B2 simulation, rather than from re-scaling A2, as was done for the UKCIP02 scenarios.

\subsection{Dynamic downscaling - use of RCM data}

The impacts due to the application of the hourly rainfall data from the Hadley Centre $25 \mathrm{~km}$ RCM are summarised in Table 3 for a range of return period flows. The results show that for seven of the catchments the percentage change becomes increasingly negative with increasing return period, with three of these having a decrease of more than $20 \%$ in the 50-year flow. Most catchments show an increase at the 1-year return period flows. It should be noted that the results are for only one scenario for one time slice, so how the change for the 2080 s relates to change in the intervening period, or the variability in the change had a number of RCM ensembles been analysed, cannot be identified. 
Table 3: $\quad$ Percentage changes for the RCM scenario.

\begin{tabular}{lcccc}
\hline Catchment & 1-year & 5-year & 20-year & 50-year \\
\hline Ouse at Skelton & 5.0 & 8.7 & 10.7 & 11.7 \\
Rea at Calthorpe Park & 13.7 & 0.3 & -14.0 & -23.4 \\
Lymn at Partney Mill & 6.1 & -2.7 & -12.0 & -18.4 \\
Thames at Kingston & 7.0 & 14.2 & 16.7 & 17.7 \\
Beult at Stile Bridge & 9.3 & -2.3 & -13.8 & -21.5 \\
Anton at Fullerton & 12.4 & 10.8 & 3.5 & -2.2 \\
Severn at Bewdley & -3.3 & -12.1 & -19.4 & -23.8 \\
Severn at Haw Bridge & -4.0 & -9.9 & -14.5 & -17.8 \\
Duddon at Duddon Hall & 17.3 & 16.9 & 16.3 & 15.7 \\
Halladale at Halladale & 14.5 & 5.0 & -6.9 & -15.2 \\
\hline
\end{tabular}

\subsection{Scenarios from other GCMs}

One of the largest single sources of uncertainty is that due to the modelling of the global climate $[15,16]$. It is, therefore, most important that scenarios of change in climate be sourced from more than one GCM. To this end, and to place the changes in peak flows simulated under the UK Hadley Centre GCM, and the UKCIP02 scenarios in particular, in context, scenarios were also derived from GCMs from Australia (CSIRO-Mk2), Canada (CGCM2), Germany (ECHAM4) and Japan (CCSR). Figure 4 shows the changes in the flood frequency curve for the Beult, by the 2080s using all these GCMs (solid lines, deliberately left unlabelled). The 30 -year flow for the baseline is about $105 \mathrm{~m}^{3} \mathrm{sec}^{-1}$, with changes under the various GCMs ranging from $+38 \%$ (to $149 \mathrm{~m}^{3} \mathrm{sec}^{-1}$ ) to $-10 \%$ $\left(90 \mathrm{~m}^{3} \mathrm{sec}^{-1}\right)$. This range of impact is large compared with, for example, the hydrological model uncertainty, estimated around $+/-5 \%$ for this catchment [16].

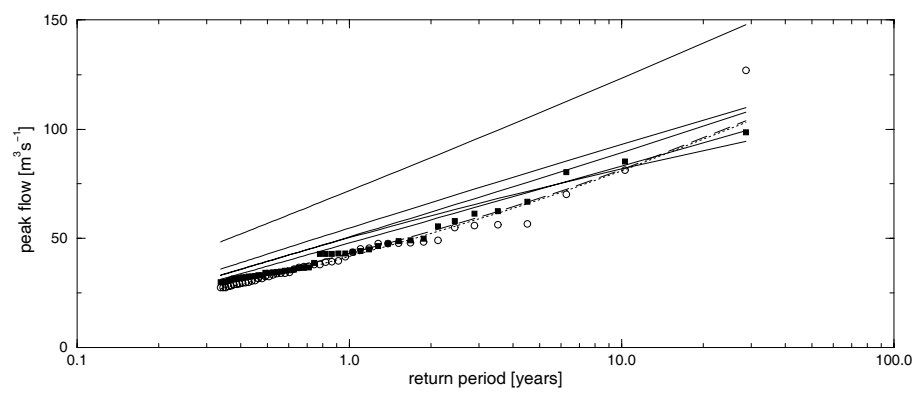

Figure 4: $\quad$ Flood frequency curves for the Beult for the current (dashed), and for the 2080s from a range of GCMs (solid lines). 


\section{Discussion}

The percentage changes in flood frequency presented here are noticeably different from those given in the earlier studies in Britain [4-6] where increases in flood frequency were modelled consistently under all scenarios. These differences derive from the scenarios being predominantly developed from an alternative, more recent version of the UK GCM.

Given these warmer and drier scenarios, any flood peaks occurring in September and October are automatically reduced due to the lower effective rainfall during these seasons, and for the larger less-responsive catchments many peaks in November and December and even January are also reduced through the need to replenish large soil moisture deficits. This is further supported by the fact that the Duddon shows increases under nearly all scenarios due to its more responsive nature and because it is in an area of significant rainfall increase in all seasons but the summer.

The pattern of changes across the future time slices also shows that any impact on peak flows is a fine balance between the seasonal changes in rainfall and the increases in evaporation, so that for the Halladale under the UKCIP02 scenarios there is a slight increase by the $2050 \mathrm{~s}$, but a decrease by the $2080 \mathrm{~s}$ at higher return periods.

The percentage changes in flows under all scenarios for the 2080s at the 20year return period are summarised in Table 4. Only two catchments show increases under all scenarios at this return period, these being the Duddon and the Anton. Equally only two catchments show decreases under all scenarios at this return period, these being the Lymn and the Beult. Both these catchments are on the eastern side of the country where there is already a fine balance between rainfall and $\mathrm{PE}$. All other catchments show a range of positive and negative change.

The ranges of changes simulated by using scenarios from five different GCMs are large for all catchments. These are expressed as percentage changes so should be related to the actual flow in the catchments listed in Table 1. In percentage terms the largest range is for the Anton; the smallest for the Duddon, where all changes are also positive. However, in terms of actual changes, the largest ranges for the 20 -year return period flow are seen in the Duddon and Halladale.

\subsection{Uncertainty}

The results presented should be seen in light of the uncertainty in a climatechange impact study. The sources of uncertainty include: future emissions of greenhouse gases; the representation of processes within the GCM; natural climate variability; scenario development (downscaling) and hydrological impact model (model structure and parameterisation).

Some of these sources of uncertainty have, to a degree, been addressed in the current study. Two of the IPCC SRES emissions scenarios [12] have been used in conjunction with statistical downscaling, and the output from five GCMs has 
been used to derive scenarios. Various downscaling techniques, both statistical and dynamic, have been applied and hydrological model uncertainty due to calibration has been discussed and quantified in an earlier report [2].

It has been found that the relative uncertainty due to the range of GCM simulations is greater than the uncertainty due to emissions, downscaling or hydrological modelling. However, it is clear that within this study, even for those areas where uncertainty has been considered it is unlikely that the full range has been sampled.

Table 4: Percentage changes for the 20-year return period flows for the 2080s.

\begin{tabular}{|c|c|c|c|c|c|c|c|c|}
\hline \multirow{2}{*}{ Catchment } & \multicolumn{4}{|c|}{ UKCIP02 } & \multicolumn{2}{|c|}{ SDSM } & \multirow{2}{*}{$\frac{\mathrm{RCM}}{\mathrm{A} 2}$} & \multirow[t]{2}{*}{ GCM range } \\
\hline & Low & $\begin{array}{l}\text { Med } \\
\text { Low }\end{array}$ & $\begin{array}{l}\text { Med } \\
\text { High }\end{array}$ & High & B2 & $\mathrm{A} 2$ & & \\
\hline Ouse & -2.2 & -3.6 & -3.8 & -4.2 & 7.0 & -3.8 & 10.7 & \\
\hline Rea & 6.4 & -2.5 & -2.6 & -5.5 & & & -14.0 & -28 to $+19 \%$ \\
\hline Lymn & -3.5 & -5.6 & -9.9 & -13.1 & & & -12.0 & -16 to $+35 \%$ \\
\hline Thames & -1.6 & -1.6 & 0.0 & 2.8 & & & 16.7 & \\
\hline Beult & -0.5 & -1.5 & -3.9 & -3.7 & & & -13.8 & -6 to $+45 \%$ \\
\hline Anton & 2.5 & 3.2 & 4.6 & 5.0 & & & 3.5 & -10 to $+88 \%$ \\
\hline $\begin{array}{l}\text { Severn } \\
\text { (Bewdley) }\end{array}$ & -2.1 & -2.7 & -5.4 & -6.7 & 10.4 & 6.8 & -19.4 & \\
\hline $\begin{array}{l}\text { Severn } \\
\text { (Haw } \\
\text { Bridge) }\end{array}$ & 1.2 & 1.2 & 3.0 & 4.4 & & & -14.5 & \\
\hline Duddon & 6.6 & 8.3 & 16.1 & 21.9 & & & 16.3 & +11 to $+57 \%$ \\
\hline Halladale & 0.1 & -0.9 & -3.1 & -4.6 & & & -8.9 & +5 to $+70 \%$ \\
\hline
\end{tabular}

\section{Conclusions}

The results of this paper, and the final project report [2], show the impacts of climate change on flood frequency in the study catchments, under the selected scenarios, to be considerably lower than those previously simulated [4-6]. This is determined primarily by the fact that the version of the Hadley Centre GCM driving the climate changes produces significantly drier summers and autumns than previous versions, so that, despite the wetter winters (on average), flood frequencies in many catchments decrease. This does not necessarily apply to those catchments that are more hydrologically responsive, i.e. steep-sided, small 
or urban catchments, but even in these the precise response is determined by the spatial and temporal detail of the climate changes.

For each of the catchments a range of climate impacts has been shown. In only a few of these is there an obvious tendency towards either a decrease (Lymn and Beult) or an increase (Halladale and Anton). All other catchments present a range of change, both positive and negative. The range of impacts in this study is wide, across catchments, time slices and scenarios.

Finally, it is important to consider all the various sources of uncertainty involved in climate change impact studies, and how this uncertainty impacts on the decision that the research informs. Steps are being taken to quantify and reduce these uncertainties, but they can never be eradicated completely.

\section{References}

[1] Calver, A., Crooks, S.C., Jones, D.A., Kay, A.L., Kjeldsen, T.R. and Reynard, N.S. (2005). National river catchment flood frequency method using continuous simulation. Report to the UK Defra, Technical Report FD2106/TR and Project Record FD2106/PR, CEH, 135pp.

[2] Reynard, N S, Crooks S M and Kay, A L. 2004. Impact of climate change on flood flows in river catchments. Final report for Defra / EA project W5B-01-050. 80pp.

[3] Crooks, S.M. and Naden, P.S. 2006. CLASSIC: a semi-distributed rainfall-runoff modelling system. Hydrology and Earth System Science. In press.

[4] Crooks, S.M., Naden, P.S., Broadhurst, P. and Gannon, B. 1996. Modelling the flood response of large catchments: initial estimates of the impacts of climate and land use change. Report to Ministry of Agriculture, Fisheries and Food, FD0412. 66pp.

[5] Reynard, N.S., Prudhomme, C. and Crooks, S.M. 1998. Climate change impacts for fluvial flood defence. Report to Ministry of Agriculture, Fisheries and Food, FD0424-C. 25pp.

[6] Reynard NS, Prudhomme C, Crooks SM. 2001. The flood characteristics of large UK rivers: potential effects of changing climate and land use. Climatic Change, 48, 343-359.

[7] Moore, R.J. 1985. The probability-distributed principle and runoff production at point and basin scales. Hydrological Sciences Journal, 30, 273-297.

[8] Moore, R J 1999. Real-time flood forecasting systems: Perspectives and prospects. In: Floods and landslides: Integrated Risk Assessment, R. Casale and C. Margottini (eds.), Chapter 11, 147-189. Springer.

[9] Hulme, M., Jenkins, G.J., Lu, X., Turnpenny, J.R., Mitchell, T.D., Jones, R.G., Lowe, J., Murphy, J.M., Hassell, D., Boorman, P., McDonald, R. and Hill, S. 2002. Climate Change Scenarios of the United Kingdom: The UKCIP02 Scientific Report. Tyndall Centre for Climate Change Research, School of Environmental Sciences, University of East Anglia 
[10] Wilby R L, Dawson, C W and Barrow, E M. 2002. SDSM - a decision support tool for the assessment of regional climate change impacts. Environmental and Modelling Software, 17, 145-157.

[11] Wilby R L, Tomlinson, O J and Dawson, C W. 2003. Multi-site simulation of precipitation by conditional resampling. Climate Research, 23, 183-194.

[12] IPCC 2000. Special report on emissions scenarios (SRES): A special of Working Group II of the Intergovernmental Panel on Climate Change, Cambridge University Press, Cambridge, UK. 599pp.

[13] Naden, P.S. 1993. Methods and techniques for peaks-over-threshold flood analysis. Report to Ministry of Agriculture, Fisheries and Food.

[14] Hosking, J.R.M. and Wallis, J.R. 1987. Parameter and quantile estimation for the Generalised Pareto distribution, Technometrics, 29, 339-349.

[15] Jenkins, G and Lowe, J. 2003. Handling uncertainties in the UKCIP02 scenarios of climate change. Hadley Centre technical note 44.

[16] Kay, A.L., Bell, V. and Davies, H. (2006) Model quality and uncertainty for climate change impacts. Contract report to the Hadley Centre. 48pp. 